\title{
Problemas laborales en plazas del Servicio Rural Urbano-Marginal en Salud (SERUMS): auto-reporte de los médicos
}

\section{Working conditions problems in the social service in medicine (SERUMS): a report from physicians involved}

Correspondencia Christian R. Mejia christian.mejia.md@gmail.com

Recibido: 16/03/2016 Aprobado: 13/04/2016

Citar como:

Mejia $C R$, Inga-Berrospi $F_{1}$ Albrecht Lezama C, Quispe García AA. Problemas laborales en plazas del Servicio Rural Urbano-Marginal en Salud (SERUMS): auto-reporte de los médicos. Acta Med Peru. 2016;33(1):82-3

\author{
Christian R. Mejia ${ }^{1,2}$, Fiorella Inga-Berrospi ${ }^{1,3}$, Carlos Albrecht Lezama ${ }^{1,4}$, Angie \\ Alejandra Quispe García1 \\ 1 Comité del Médico Joven del Consejo Nacional, Colegio Médico del Perú. Lima, Perú. \\ 2 Escuela de Medicina Humana, Universidad Continental. Huancayo, Perú. \\ 3 Universidad Nacional Mayor de San Marcos. Lima, Perú. \\ 4 Universidad Peruana Cayetano Heredia. Lima, Perú.
}

\section{Sr. Editor:}

Es conocido que cada año miles de médicos y otros profesionales de la salud realizan el Servicio Rural Urbano-Marginal en Salud (SERUMS), este programa se da hace más de 30 años con el propósito de ofrecer atención integral de salud a las poblaciones más vulnerables y de escasos recursos; asimismo, constituye una condición necesaria para ejercer la profesión en entidades públicas, acceder a los programas de segunda especialización o subvenciones académicas del estado [1].

Sin embargo, existen reportes previos que muestran que no siempre el SERUMS otorga las condiciones necesarias para que estos profesionales cumplan adecuadamente con su labor, algunos reportes locales muestran que se da una deficiente cobertura de aseguramiento hacia los profesionales que lo realizan [2], así como, conflictos con el personal nombrado de los establecimientos de salud, problemas administrativos y accidentes, lo que genera la disminución en la intención de trabajar en zonas rurales luego de haber culminado el programa [3]. Esta problemática ha sido ampliamente descrita en estudios y discutida en reuniones denominadas convenciones de médicos SERUMS, estableciendo propuestas de mejora [4].

Es en ese contexto que el Colegio Médico del Perú -en cumplimiento de sus funciones de velar por el bienestar de sus colegiados y a través de su Comité del Médico Joven del Consejo Nacional sumado al Servicio de Defensa Legal del Médico (INDELMED)-; estableció durante los meses de enero y febrero del presente un sistema básico de auto reporte de problemas laborales de algunas plazas SERUMS, esto como parte de un estudio piloto. En donde se obtuvo reportes de diversos tipos de denuncias desde las distintas sedes a nivel nacional, siendo las más frecuentes las agresiones verbales, seguidas de las psicológicas y de las físicas; representando en más del $80 \%$ de los casos problemas de acoso laboral y hostilidad por parte del personal propio de los establecimientos de salud. Con estos datos se ha podido generar un listado de las plazas que han tenido problemas durante la realización del SERUMS 2015-I. Figura 1. 


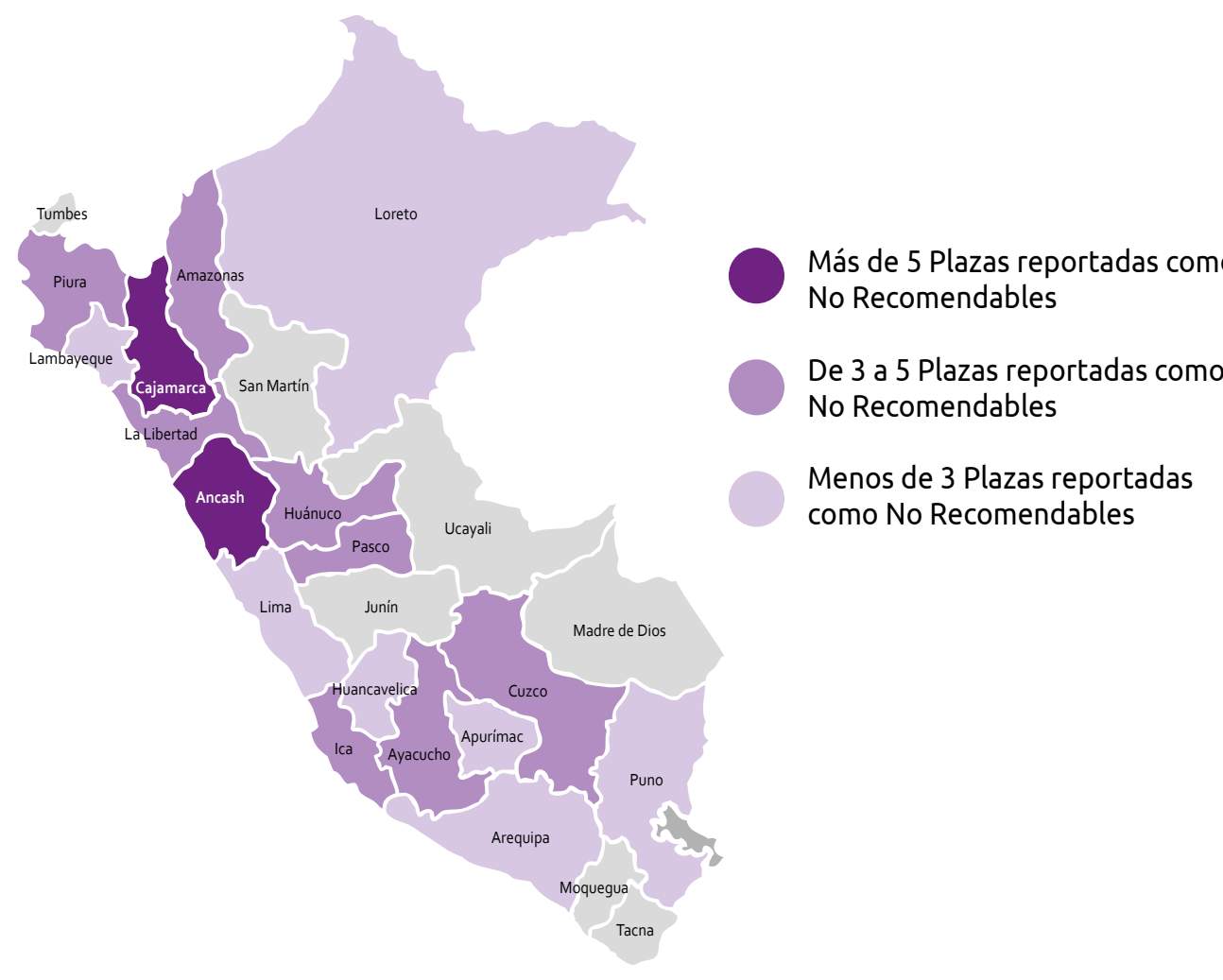

Figura 1. Mapa nacional de regiones del Servicio Rural Urbano-Marginal en Salud (SERUMS) donde se han reportado problemas laborales, 2015.

Estos resultados no son extrapolables a toda la red asistencial, ya que si bien un reporte no puede catalogar a la sede como conflictiva en su totalidad, esto es un indicativo de que existen problemas en dicha sede. Recalcando que esto se basa en los reportes que se han generado por los médicos que ahí realizan su actividad asistencial siendo esta información verificada por los representantes del Comité Médico Joven o el INDELMED, por lo que estos reportes tienen un sustento institucional. Esto debe ser corroborado de forma objetiva por la institución correspondiente, pues de confirmarse esta situación se deberían plantear estrategias de mejora, y de ser un caso reiterativo deberían retirarse dichas plazas del proceso, de ser necesario. Esto debido a que un adecuado ambiente laboral es necesario para que los profesionales se desenvuelvan adecuadamente, siendo más probable obtener mejores resultados laborales cuando las personas se sienten parte de un grupo de trabajo con un clima organizacional satisfactorio y con las competencias adecuadas para desempeñarse laboralmente [5].

Fuente de financiamiento: Autofinanciado.

Conflictos de interés: los autores declaran no tener conflictos de interés con la publicación de este artículo.

\section{REFERENCIAS BIBLIOGRÁFICAS}

1. Ministerio de Salud. Ley del Servicio Rural y Urbano marginal de salud. Ley Nº 23330. Diario Oficial El Peruano. 1981.

2. Mejía CR, Quiñones-Laveriano DM, Espinoza KG, QuezadaOsoria C. Deficiente cobertura de aseguramiento en médicos durante el servicio rural y urbano-marginal en salud. Rev Peru Med Exp Salud Publica. 2013;30(2):220-3.

3. Mejía CR, Quiñones-Laveriano DM. SERUMS y la migración de médicos: a propósito de una cohorte de médicos de Lima [carta]. Rev Peru Med Exp Salud Publica. 2015;32(2):405-6.

4. Inga-Berrospi F, Taype-Rondàn A, Purizaca-Rosillo N. La problemática del médico serumista en el Perú: conclusiones de la Segunda Convención Nacional de Médicos Serumistas, 2013. An Fac med. 2014;75 (3):271-2.

5. Chiang M. Clima organizacional y satisfacción laboral en un establecimiento de salud estatal: hospital tipo 1 . Theoria. 2007;16(2):61-76. 